\title{
Impairment en de controlerend accountant
}

\section{André Bindenga}

SAMENVATTING In dit artikel wordt behandeld welke aspecten voor de controlerend accountant zijn verbonden aan impairment van activa. Daartoe zal een onderscheid worden gemaakt tussen de situatie waarbij de ondernemingsleiding van oordeel is dat impairment noodzakelijk is en de situatie dat de accountant alleen dit oordeel heeft. Daarna wordt met name ingegaan op impairment van materiële vaste activa en goodwill. Tot slot wordt de aanpak van de controle gereleveerd.

\section{Inleiding}

In dit artikel zal worden ingegaan op de gevolgen die de recente aandacht voor impairment heeft voor de werkzaamheden van de accountant. Ik beperk mij in dit verband tot de accountantscontrole van de jaarrekening. De werkzaamheden van accountants in de adviserende functie, bij fusies en acquisities en bij due diligence-onderzoeken vallen dus buiten het bestek van deze beschouwing. Onder impairment versta ik een incidentele, bijzondere afwaardering van activa op het moment van het opstellen van de jaarrekening. Er zijn in de nationale en internationale regelgeving voorschriften opgenomen wanneer een dergelijke afwaardering noodzakelijk is. In dit speciale nummer van het maandblad is aan deze voorschriften reeds de nodige aandacht geschonken (Vergoossen, 2004), zodat deze hieronder niet opnieuw worden behandeld.

Prof. Dr. A.J. Bindenga RA is emeritus hoogleraar Accountancy aan de Erasmus Universiteit Rotterdam, alsmede oud-voorzitter van Ernst \& Young en oud-voorzitter van het Koninklijk NIVRA.

\section{Op welke wijze heeft de accountant met impairment te maken?}

Ik onderscheid twee mogelijke omstandigheden, waarbij de accountant kan worden geconfronteerd met het verschijnsel 'impairment':

- Indien de ondernemingsleiding van oordeel is dat een afwaardering nodig is van een materieel of immaterieel vast actief.

- Indien de accountant zelf van oordeel is dat een afwaardering nodig is van een materieel of immaterieel vast actief.

In het eerste geval zal de ondernemingsleiding zelf de hoogte van de afwaardering vaststellen en zal de accountant deze dienen te controleren. Van verschillende kanten (Knoops, 2004) is erop gewezen dat de berekening van de afwaardering zeer subjectieve elementen bevat en het is de vraag of de accountant niet zou moeten eisen dat de berekening wordt uitgevoerd door een onafhankelijke organisatie. Vooral als het gaat om de afwaardering van een immaterieel actief, met name van geactiveerde goodwill, is dit zeer aan te bevelen. Het is volgens nationale en internationale controlerichtlijnen overigens niet toegestaan dat de controlerend accountant zelf of de organisatie waaraan hij verbonden is, de berekening uitvoert (Bindenga, 2003). De controle van de accountant op de berekening van de afwaardering richt zich vanzelfsprekend op de rekenkundige juistheid van de berekening, hetgeen het eenvoudigste onderdeel van de controle is. Veel moeilijker is de beoordeling van de gemaakte veronderstellingen en subjectieve inschattingen.

In het tweede geval kan er sprake zijn van een situatie waarbij de ondernemingsleiding geen aanleiding ziet tot een afwaardering, maar de accountant van mening is dat zulks wel dient te geschieden. De accountant zal dan zelf de berekening dienen uit te voeren en te maken krijgen met de hierboven gesignaleerde veron- 
derstellingen en subjectieve inschattingen. Indien hij zich strikt zou houden aan de nationale en internationale controlerichtlijnen zou hij overigens een onafhankelijke organisatie de opdracht moeten geven om de berekening uit te voeren, omdat hij bij de controle anders zijn eigen werk gaat beoordelen. Feit blijft echter dat het constateren of impairment noodzakelijk is, door hemzelf geschiedt. Het constateren kan toch niet op andere wijze plaatsvinden dan zelf een inschatting te maken. Naar mijn mening ligt hier dus een vrijwel onoplosbaar probleem voor de onafhankelijkheid van de accountant.

\section{Enkele opmerkingen over de impairment van materiële vaste activa}

Voor wat betreft de soorten impairment kan onderscheid worden gemaakt in:

- bijzondere waardeverminderingen van materiële vaste activa, met name duurzame productiemiddelen;

- bijzondere waardeverminderingen van immateriële vaste activa, met name goodwill;

- bijzondere waardeverminderingen van financiële vaste activa.

Op bijzondere waardeverminderingen van financiële vaste activa ga ik in dit artikel niet in.

De eerste categorie is voor Nederlandse accountants niet zo bijzonder revolutionair. Al vele jaren is de waarderingsgrondslag kostprijs of lagere marktwaarde bekend. Onder de lagere marktwaarde wordt dan verstaan de hoogste van directe of indirecte opbrengstwaarde. Dit laatste begrip is afkomstig uit de theoretische beschouwingen van de vervangingswaardetheorie en opgenomen in de Nederlandse wetgeving onder de naam bedrijfswaarde. De directe opbrengstwaarde van een materieel vast actief is dikwijls niet al te moeilijk vast te stellen aan de hand van beschikbare informatie over de opbrengst van gelijke objecten of door middel van taxatie. De vaststelling van de bedrijfswaarde gaat evenwel gepaard met subjectieve inschattingen over toekomstige kasstromen die het betreffende actief kan opleveren. Bij productieinstallaties dient men zich een voorstelling te maken van de hoeveelheid te produceren eenheden en de verkoopprijzen hiervan, alsmede van de complementaire kosten om de eenheden voort te brengen. Vele onzekerheden zijn hieraan verbonden.

In elk geval zijn bijzondere waardeverminderingen van materiële vaste activa geen onbekend verschijnsel. Het betreft elke tot uitdrukking gebrachte daling van de boekwaarde uit andere hoofde dan systematische afschrijving. Er zijn vele oorzaken voor een waardevermindering, zoals valuta-, koers- en prijswijzigingen, schattingsherzieningen, gewijzigde aanwending of plotseling optredende economische of technische slijtage.

Indien de ondernemingsleiding zelf van mening is dat een bijzondere waardevermindering aan de orde is, dan zal de accountant de toereikendheid van de hoogte dienen te beoordelen. De grote subjectiviteit en de mate van onzekerheid van inschattingen zal hierbij zijn grootste probleem zijn. Moeilijker wordt het als de accountant van oordeel is, dat er aanleiding is tot een bijzondere waardevermindering, maar dat de ondernemingsleiding hiervan niet overtuigd is. Men kan deze situatie vergelijken met verschillen in inzicht tussen ondernemingsleiding en accountant bij de signalering van dreigende discontinuïteit. Hierbij wordt in het algemeen nog een aantal mogelijkheden onderscheiden, zoals:

- ondernemingsleiding is positief en de accountant onzeker over de toekomst;

- ondernemingsleiding is positief en de accountant negatief over de toekomst;

- ondernemingsleiding is onzeker en de accountant is negatief over de toekomst.

Het behoeft geen betoog dat in dit soort situaties er gevolgen zijn voor de af te geven accountantsverklaring. In veel gevallen zou men moeten komen tot een niet goedkeurende accountantsverklaring.

Bij verschil van mening over een bijzondere waardevermindering van materiële vaste activa geldt in principe hetzelfde, ook met dezelfde gevolgen. Deze bestaan uit een verlies van vertrouwen in de onderneming bij analisten en beleggers en tot een aanmerkelijke schade voor aandeelhouders. De aansprakelijkheid van de accountant en mogelijke claims van derden zijn ook aan de orde. Men moet als accountant derhalve wel stevig in de schoenen staan om in zo'n geval een afkeurende verklaring te geven. In elk geval is het gewenst een second opinion te verkrijgen. De accountant is niet altijd voldoende deskundig en zal dan wel genoodzaakt zijn deskundigen in te schakelen. Hij blijft echter te allen tijde ongedeeld verantwoordelijk voor zijn verklaring.

\section{Enkele opmerkingen over de impairment van immateriële vaste activa}

Een bijzondere waardevermindering van immateriële vaste activa en dan met name van geactiveerde good- 
will, is voor de Nederlandse accountant wel een verschijnsel van recente datum. In het verleden werd betaalde goodwill veelal ten laste van het eigen vermogen gebracht en waren waardeverminderingen niet aan de orde. Nu de nationale en internationale regelgeving activering van betaalde goodwill verplicht stelt en zelfs zonder hierop systematisch af te schrijven (Krens, 2003) wordt de situatie echter anders.

Een vergelijking met de waardevermindering van materiële vaste activa leert dat bij waardevermindering van goodwill meestal geen sprake is van een directe opbrengstwaarde. Het gaat dus vrijwel altijd om een lagere indirecte opbrengstwaarde ofwel een geheel op de toekomst gerichte waarde.

Volgens de huidige regelgeving kan geactiveerde goodwill uitsluitend betaalde goodwill betreffen en geen eigen goodwill, dikwijls zelf gecreëerde goodwill genaamd. De achtergrond van dit laatste verbod is dat een dergelijke post niet voldoet aan de kenmerken van een actief en bovendien kan de waarde niet betrouwbaar worden vastgesteld. De argumentatie om betaalde goodwill wel als actief aan te merken, is dat de bij de aankoop van een onderneming overeengekomen prijs een min of meer objectief gegeven is. De betaalde goodwill is het verschil tussen deze prijs en de nettovermogenswaarde en is daarom ook min of meer objectief. Indien men goodwill echter zou omschrijven als de contante waarde van de in de toekomst door een onderneming te behalen overwinst is het de vraag of het vorenbedoelde rekenkundige verschil overeenkomt met de in feite verworven goodwill. Een overnameprijs wordt immers beïnvloed door vele factoren en is vrijwel altijd een gevolg van onderhandelen. Het rekenkundige verschil dat men goodwill noemt, is onderhevig aan dezelfde factoren. Het vraagstuk van de impairment zou dan ook al direct na de verwerving aan de orde kunnen komen als men zich realiseert dat goodwill uitsluitend de contante waarde van de toekomstige overwinst is. In de praktijk betekent dit dat accountants al direct na een overname zich de vraag moeten stellen of impairment noodzakelijk is. Het antwoord op deze vraag is echter niet eenvoudig (Krens, 2000).

Bovendien stuit men hierbij op het vraagstuk van de vermenging van gekochte en zelfgegenereerde goodwill. Een impairment zou namelijk niet hoeven plaats te vinden als de geactiveerde goodwill gerechtvaardigd wordt door de contante waarde van de toekomstige kasstroom van de zogenaamde kasgenererende eenheid, waaraan de goodwill toe te rekenen is. Hierin kan echter eigen goodwill van de onderneming, die de goodwill heeft betaald, zijn begrepen. Dit activeren van eigen goodwill is ongewenst, maar zou op deze wijze wel in aanmerking worden genomen. Kortom, de controlerend accountant heeft het niet gemakkelijk bij het vaststellen van de wenselijkheid van impairment en het wordt nog moeilijker bij het controleren van een eenmaal toegepaste impairment. Het valt overigens te hopen, dat het in de toekomst weer terugnemen van een toegepaste impairment niet langer zal worden toegestaan, aangezien de mogelijkheden tot winststuring en -manipulatie hierbij sterk aanwezig zijn.

\section{Aanpak van de controle}

Het is tegenwoordig gebruikelijk de accountantscontrole te richten op het onderkennen van risico's en het beheersen van risico's. De concrete werkzaamheden van de controlerend accountant hangen dan af van de sterkte en zwakte van de beheersingsstructuur en -maatregelen. Kan deze benadering ook plaatsvinden in het kader van de beoordeling van de wenselijkheid van impairment, dan wel de controle van een toegepaste impairment?

In het algemeen kan worden gesteld, dat deze moderne controlebenadering bruikbaar is voor verschillende controleobjecten, maar dat professionele oordeelsvorming de kern van het controleproces blijft (Gortemaker/Wallage, 2003). Ik meen dat dit bij uitstek het geval is bij de controle van waardeverminderingen.

Ik geef een voorbeeld: Ondernemingen in een bedrijfstak, waar de resultaten niet sterk afhangen van het gebruik van duurzame bedrijfsmiddelen, zijn bijvoorbeeld uitgeverijen, financiële instellingen en dienstverlenende bedrijven. Stel dat een onderneming in een dergelijke bedrijfstak een andere onderneming overneemt. De overnameprijs bestaat vrijwel uitsluitend uit goodwill. Bij de onderhandelingen tijdens het overnameproces is bij de overnemende onderneming diepgaand gesproken over de motieven om tot een overname over te gaan. De accountant van de betreffende onderneming neemt kennis van interne rapporten, verslagen van het besturend en toezichthoudend orgaan, en dergelijke. Hij constateert dat het belangrijkste motief voor de overname is het uit de markt halen van een concurrent om de eigen omzet zeker te stellen. Het overgenomen bedrijf heeft de afgelopen jaren een redelijk resultaat gemaakt en men verwacht dat het bedrijf dat ook in de toekomst wel zal behalen. Uitsluitend het resultaat van het bedrijf rechtvaardigt op zich echter geenszins de overname- 
prijs. Hieruit blijkt derhalve dat de overnemende onderneming bereid is een premie te betalen om gebruik te maken van overnamevoordelen, namelijk het zeker stellen van de eigen omzet. Kort na de overname wordt het overgenomen bedrijf volledig geïntegreerd in de eigen bedrijfsactiviteiten en al zeer snel is het resultaat van het overgenomen bedrijf niet meer afzonderlijk te bepalen. Op de balans van het overnemende bedrijf prijkt wel een groot bedrag aan goodwill waarop niet systematisch wordt afgeschreven volgens de voorschriften van de ontwerpstandaard 'Business Combinations' van de International Accounting Standards Board. De resultaten van het geïntegreerde bedrijf zijn niet noemenswaardig hoger dan van het overnemende bedrijf in het verleden en uit begrotingen voor de komende jaren blijkt dat hierin weinig zal veranderen.

De controlerend accountant van het geïntegreerde bedrijf vraagt zich af of een impairment van goodwill dient te geschieden. Hij overweegt dat als kasgenererende eenheid slechts de gehele onderneming kan worden gekarakteriseerd. In de discussie met het management blijkt dat men niet van plan is een impairment toe te passen, omdat de berekende goodwill een objectief gegeven is als de prijs die tot stand is gekomen in onderhandeling met derden.

Wat moet het standpunt van de controlerend accountant zijn? Wel of geen impairment? Een goedkeurende verklaring of een beperking of zelfs een afkeurende verklaring?

Stel dat de accountant op goede gronden vertrouwen heeft in de prognoses, inschattingen en begrotingen van de betreffende onderneming. Stel dat hij een inschatting kan maken van de contante waarde van de begrote kasstroom van het overnemende bedrijf vóór de overname en op deze manier een benadering kan maken van de aanwezige zelfgegenereerde goodwill vóór de overname. Stel dat hij vervolgens hetzelfde doet nà de overname en nà de integratie van het overgenomen bedrijf. Stel dat hij vervolgens geen noemenswaardig verschil constateert. Moet hij de conclusie trekken dat het bedrag an betaalde goodwill volledig van de balans moet verdwijnen? Indien dit niet geschiedt, moet hij dan een afkeurende verklaring geven? Of moet hij accepteren dat de voor de overname bestaande goodwill mede in aanmerking mag worden genomen bij de impairment-test? De International Accounting Standards Board heeft immers aangegeven dat het niet mogelijk is dit effect te vermijden (IASB, 2002).
De lezer zal constateren dat in het voorgaande vele vragen zijn opgeworpen. Ik meen dat er geen ondubbelzinnige antwoorden te geven zijn. Althans niet op grond van de huidige regelgeving. Op grond van zijn professionele oordeelsvorming zal de accountant echter moeten concluderen dat in dit voorbeeld in feite sprake is van een afkoopsom aan een concurrent die bereid is zijn positie op te geven. Zo'n afkoopsom dient als kosten te worden aangemerkt en niet eeuwig als goodwill op de balans te blijven staan.

In het bovenstaande voorbeeld ga ik er eenvoudigheidshalve aan voorbij dat het moeilijk is prognoses en begrotingen te beoordelen en dat de accountant eigenlijk voor een gedeelte zijn eigen werk controleert. En bovendien zijn er nog veel complexere situaties dan de bovenstaande.

De lezer zal zich afvragen of er wellicht toch aanwijzingen te geven zijn die de accountant bij zijn controle behulpzaam kunnen zijn. Puttend uit eigen ervaringen bij zowel grote als kleine ondernemingen kan ik met betrekking tot goodwill het volgende opmerken. In veel gevallen is het raadzaam diepgaand te onderzoeken wat de motieven van een verkopende partij zijn om afstand te doen van zijn onderneming. Dikwijls gaat het om bedrijven die jarenlang uitstekende resultaten hebben laten zien, maar op korte of middellange termijn tegenwind krijgen. Kopers weigeren dit soms in te zien, terwijl de verkoper zich dit maar al te goed bewust is. Op een hoogtepunt in de resultatenontwikkeling wordt het bedrijf afgestoten en er wordt veel goodwill betaald. Na verloop van tijd blijken de ingeschatte rooskleurige voordelen van de overname uit te blijven en de accountant zal zich moeten afvragen wat hiervan de oorzaak is. Zo kan hij op het spoor van een noodzakelijke impairment komen.

Concluderend kan worden gesteld, dat het werk van de controlerend accountant er niet gemakkelijker op wordt. Ik meen zelfs dat hij in een onmogelijke positie kan komen te verkeren. Het is te hopen dat het direct afboeken van betaalde goodwill ten laste van het eigen vermogen weer zeer snel mogelijk zal worden. Er zijn vele argumenten voor in stelling te brengen, maar deze vallen buiten het bestek van dit artikel.

\section{Conclusie}

In bovenstaande beschouwing is aan de orde gesteld op welke wijze de controlerend accountant met impairment heeft te maken. In vrijwel alle gevallen van impairment is er sprake van subjectieve veron- 
derstellingen en inschattingen. De impairment van materiële vaste activa is niet nieuw, maar is daarom nog niet objectief. Vooral bij verschillen van mening tussen ondernemingsleiding en accountant zal de accountant met goede argumenten moeten komen om een niet goedkeurende verklaring bij de jaarrekening te geven. De impairment van immateriële vaste activa, met name van goodwill, is in Nederland een relatief nieuw verschijnsel. De accountant heeft het hierbij niet gemakkelijker gekregen, omdat de subjectiviteit nog aanmerkelijk groter is dan bij materiële vaste activa. De controle van impairments is derhalve bij uitstek een zaak van professionele oordeelsvorming, dat de kern van het controleproces blijft. Aan de hand van een voorbeeld heb ik de aanpak van de controle toegelicht.

\section{Literatuur}

Bindenga, A.J., (2003), Functie en taak van de accountant, in: Handboek Accountancy, Deventer, Suppl. 1, december.

International Accounting Standards Board, (2002), Exposure Draft ED 3 , Business Combinations.

Gortemaker, J.C.A. en Ph. Wallage, (2003), Accountantscontrole gebaseerd op bedrijfsrisico's, in: Handboek Accountancy, Deventer.

Knoops, C.D., (2004), Bijzondere waardeverminderingen: mogelijkheden tot resultaatsturing?, in: Maandblad voor Accountancy en Bedrijfseconomie, jg. 78, nr. 1/2, pp. 2-4.

Krens, F., (2003), Waardevermindering van geactiveerde goodwill, in: M.N. Hoogendoorn, J.C.A. Gortemaker, E.A. de Knecht, H.C. Kocks en Chr. de Kruis (redactie), Maatschappelijk Aanvaardbaar, opstellenbundel aangeboden aan Prof. Dr. A.J. Bindenga RA, Deventer, 2003, pp. 109-120. Krens, F., (2000), Goodwill, in: Handboek Accountancy, Deventer.

Vergoossen, R.G.A., (2004), Bijzondere waardevermindering van vaste activa in de regelgeving, in: Maandblad voor Accountancy en Bedrijfseconomie, jg. 78, nr. 6, pp. 261-268. 